\title{
IS SOCIAL PROGRESS SUBJECT TO CULTURAL INFLUENCES? ARGUMENTS FOR CONSIDERING CULTURAL CHARACTERISTICS AS INPUTS FOR SOCIAL POLICY DESIGN AND IMPLEMENTATION
}

\author{
Dr. Horațiu DAN \\ Assistant Professor, \\ Faculty of European Studies, \\ Babeș-Bolyai University, Cluj-Napoca, Romania \\ horatiu.dan@ubbcluj.ro
}

\begin{abstract}
:
A deep comprehension of the relation between the cultural characteristics exhibited by society and social issues can have a strong positive effect on the development of more effective and efficient, culturally adapted social policies. This paper focuses on the topic from an EU perspective, recognizing that better coordination of Member States' social policies and the implicit increase in social integration represent key factors for the broader European integration process (and its objectives of a monetary, fiscal or social nature) and cannot be reached without a full understanding of how cultural differences shape the EU's economic and social environment. Aimed at identifying relevant links between, on one hand, the cultural dimensions defined and measured by sociologists lead by Hofstede and Schwartz and, on the other, social progress as defined and measured by the Social Progress Index, this paper shows that indeed some cultural characteristics like Hofstede's indulgence and Schwartz's embeddedness and egalitarianism are of causal relevance for the social development process. Data indicate that the pivotal role in this causal link is played by the total social expenditures/ GDP per capita, which seem to be influenced by the above mentioned cultural characteristics, further transmitting this influence via their connection with elements relevant to social progress.
\end{abstract}

Keywords: social policy; social progress; cultural dimensions 
Issue no. 22/2017

\section{Preliminaries}

The comprehensive understanding of the links between culture and social issues is of crucial importance to the sound development of policies that are adapted to the cultural environment, thus increasing their potential for effectiveness and efficiency. Bearing this in mind, this study aims at identifying such connections with the purpose of contributing to determining their nature and thus providing additional information allowing policymakers to adjust their policy approach in such a way that cultural elements represent a catalyst and not a barrier to socio-economic progress and structural reforms.

Moreover, from an EU perspective, coordinating Member States' social policies and, consequently, achieving an increased level of social integration plays a pivotal role and cannot be done without fully understanding how culture and the existent cultural differences influence the economic and social environment of the EU. Furthermore, this should be viewed as an intermediary objective for several EU objectives, including strengthening the monetary integration process, as increased social integration, especially regarding employment creation, capacity to maintain domestic social safety nets and social transfers at an EU level, is decisive for resolving Eurozone shortcomings (Grahl and Teague, 2013).

Finally, national cultural characteristics are highly relevant for the development of processes and increasing integration in fields such as social entrepreneurship and entrepreneurial culture, taking into consideration the convergence theories presented by Albescu and Maniu (2015) and managerial challenges similar to those identified by Ibănescu, Racolţa-Paina and Ionescu (2015). This is especially pertinent since the EU enlargement has generated increased economic and social diversity (Păun, 2013).

In this context, the paper focuses on identifying potential causal relations between cultural national dimensions or values and social progress. However, some conceptual clarifications need to be laid out first, as the notion of causation is heterogenous enough to pose potential differences in perception. For the purpose of this research, I adhere to the 
vision of Gerring (2005), who proposes an understanding of the concept borrowed from Bayesian inference, postulating that a cause raises the probability of an event. However, all results must be interpreted with the full awareness of the fact that, besides cultural elements, social development is influenced by a wide variety of factors including the institutional and legal framework, the electoral system, wealth and wealth creation processes, policy spill-overs or European integration. Consequently, social progress is the outcome of numerous multidirectional interactions operating in a highly complex socioeconomic system, which makes the isolation the effects induced by one particular cause a laborious endeavor.

Furthermore, since the paper is studying the topic from the perspective of the European integration process, the investigation is focused on data pertaining to EU Member States in an attempt to isolate some of the institutional architecture and democracy linked elements that could act as lurking variables.

\section{Measuring Culture - a Review of the Hofstede and Schwartz Models}

A couple of decades of socio-anthropologic research about the cultural characteristics of peoples have led to the crystallization of a series of dominant theories that can have numerous applications in the fields of political science and economics. Out of these, this study relies on the theories and measurements of national cultural dimensions as resulting from the comprehensive works of Hofstede (2001, 2011), Hofstede, Hofstede and Minkov (2006) and Schwartz (1999, 2006). The objective is to identify meaningful connections between national cultural dimensions or values and key aspects regarding social policies and their consequences.

Based on over 100,000 questionnaires applied to IBM employees from 50 countries, Hofstede's studies allow the analysis of cultural characteristics on a national level (Hofstede, 2001, 2011; Hofstede, Hofstede and Minkov, 2010) and represent the 
groundwork for the measurement of six cultural dimensions proposed by Hofstede and his collaborators, as described in Hofstede (2011):

1. power distance - this dimension measures the degree in which less powerful members of society accept and even expect an uneven distribution of power within the group;

2. uncertainty avoidance, which measures the degree of tolerance to ambiguity and the unknown;

3. individualism (vs. collectivism) - this dimension measures the degree in which the members of society are integrated into groups;

4. masculinity (vs. femininity) is a dimension that measures where a specific society places itself along a spectrum characterized by two extremes: one of masculine values (like competition, ambition, or the connection between success and material reward) and the other of feminine values (among which one can distinguish cooperation, modesty and emphasizing the quality of life);

5. long term orientation (vs. short term orientation), a dimension based on the relation that is established within a society between perspectives, objectives and expectations at different intervals of time. A society that is characterized as being long term oriented will concentrate on the future, while a society with a short term orientation will focus its attention on the near future, present, or even past;

6. indulgence (vs. restraint) - this dimension is based on the contrast between the predisposition for indulgence, "that allows relatively free gratification of basic and natural human desires related to enjoying life and having fun" (Hofstede, 2011), whereas, in contrast, restraint "stands for a society that controls gratification of needs and regulates it by means of strict social norms" (Hofstede, 2011).

The greatest merit of Hofstede's and his collaborators' research resides in the development of a coherent instrument that allows measurement and comparison of cultural dimensions at a national level, thus transcending the abstract level of many previous 
Issue no. 22/2017

theories. Moreover, the results of Hofstede's research and the relative accuracy of the model has been confirmed by the application of questionnaires on different groups of respondents (Jones, 2007).

The other cultural theory that this study is based on due to its capacity to facilitate international cultural comparisons was elaborated by Schwartz (1999), whose research led to the formulation of a model revolving around basic human values, i.e. a set of seven classes of values distributed along three dimensions, as following:

The first such bipolar dimension refers to the values that govern the relation with the group by focusing either on the independent existence of the individual via intellectual autonomy (i.e. the desire of individuals to follow their own ideas) and/or affective autonomy (i.e. the valorization of positive affective aspects, such as pleasure or a varied and interesting life) or on conservative values which place emphasis on maintaining the status quo and are opposing interferences in the traditional order, thus generating what Schwartz calls incorporation or embeddedness.

The dimensional construction continues with a perspective on egalitarianism as expressed by components governing social interaction and interdependency, varying from the adhesion to hierarchic values that legitimize the unequal distribution of powers, roles and resources (hierarchy) to the recognition of the fact that all members of society are equal from a moral standpoint and thus leading to an internalization of a commitment towards promoting the wellbeing of others (egalitarianism).

The Schwartz cultural model is completed by a third dimension, focusing on the interaction between humanity and the natural and social environment, the relation being influenced by either mastery and control, with the embedded values concentrating on adopting an assertive attitude in the desire to succeed, or harmony, translating in harmony with nature and the recognition of a world of beauty.

With the help of questionnaires applied in 73 countries (Schwartz, 2006), Schwarz's theory has transcended a purely theoretical state and led to both complex 
Issue no. 22/2017

measurements of cultural manifestations at a national level and the creation of an instrument that allows international comparison.

Hofstede's and Schwartz's pioneer academic contributions have opened up a wide range of research directions in a variety of disciplines, but especially in political studies, economics and management - for more details and applications see Steenkamp (2001), Richardson (2008), Racolța-Paina and Ionescu (2010), Dan (2015). In line with this trend, my paper, a part of a more extended research on how cultural manifestations influence socio-economic processes and their outcomes, aims at discovering and analyzing potential links between national culture and social progress.

\section{From Cultural Dimensions to Social Progress - in Search of a Connection}

According to Porter (2013), "social progress depends on the policy choices, investments, and implementation capabilities of multiple stakeholders - government, civil society, and business", actions that take place within the framework of governance structures characterized by juxtaposed loci of political autonomy and an ever-increasing network of actors (Ciceo, 2010). In this context, the paper aims at determining whether cultural characteristics influence social conditions via the policy choice channel, thus providing with additional insight on understanding the complex mechanisms that drive social progress and, ultimately, contributing to the effort of designing, at an EU level, a more effective and efficient socio-economic integration process.

The 2016 version of the Social Progress Index published by Porter and Stern (2016) is a comprehensive evaluation of a multitude of social indicators divided in three pillars (basic human needs, foundations of wellbeing and opportunity) and provides not only with a highly relevant description of social conditions in 160 countries from all over the globe, but also with an extremely useful tool for international comparison across twelve dimensions: 
- $\quad$ within the basic human needs pillar: nutrition and basic medical care, water and sanitation, shelter, personal safety;

- within the foundations for wellbeing pillar: access to basic knowledge, access to information and communications, health and wellness, environmental quality;

- within the opportunity pillar: personal rights, personal freedom and choice, tolerance and inclusion, access to advanced education (Porter and Stern, 2016).

Using the data provided by the Social Progress Index, Eurostat social expenditure figures and the cultural dimension measurements on a national level resulting from the research published in Hofstede (2001, 2011), Hofstede, Hofstede and Minkov (2010) and Schwartz $(1999,2006)$, this paper investigates the correlations between culture and social progress with the objective of identifying potential connections that would provide with relevant insight on such socio-cultural processes. Fully aware of the fact that correlation does not necessarily imply causation, the analysis recognizes the need of reaching beyond mere identification of association by investigating some logical criteria that are pertinent for providing the normative basis of causal arguments, as presented in Gerring (2005).

With this in mind, let us proceed with the analysis of the correlation results between the components measured by the Social Progress Index and the Member States' cultural dimensions defined and measured by Hofstede, as presented in Table 1 below $^{17}$.

The assessment of correlation strength is to be made according to the prescription of Zady (2000) and Asuero, Sayago and Gonzalez (2006), considering levels between 0.9 and 1 as corresponding to very high correlation, between 0.7 and 0.89 to high correlation and between 0.5 and 0.69 to moderate correlation. Similar levels are considered by Taylor (1990). Levels below 0.5 are not to be considered as relevant for our purpose.

\footnotetext{
${ }^{17}$ Croatia, Cyprus, Luxembourg and Malta are absent due to the lack of available data.
} 
Issue no. $22 / 2017$

Table 1: Association levels between the components of the Social Progress Index and Hofstede's cultural dimensions in the European Union

\begin{tabular}{|c|c|c|c|c|c|c|}
\hline & $\begin{array}{l}\text { Power } \\
\text { distance }\end{array}$ & $\begin{array}{l}\text { Individualism (vs. } \\
\text { collectivism) }\end{array}$ & $\begin{array}{l}\text { Mascul } \\
\text { inity }\end{array}$ & $\begin{array}{l}\text { Uncertainty } \\
\text { avoidance }\end{array}$ & $\begin{array}{l}\text { Long term } \\
\text { orientation }\end{array}$ & $\begin{array}{l}\text { Indulgence (vs. } \\
\text { restraint) }\end{array}$ \\
\hline $\begin{array}{c}\text { Social } \\
\text { Progress } \\
\text { (overall) }\end{array}$ & -0.60 & 0.48 & -0.14 & -0.50 & -0.28 & 0.83 \\
\hline $\begin{array}{c}\text { pillar 1: } \\
\text { Basic } \\
\text { Human } \\
\text { Needs }\end{array}$ & -0.49 & 0.40 & -0.01 & -0.47 & -0.15 & 0.73 \\
\hline $\begin{array}{c}\text { Nutrition } \\
\text { and } \\
\text { Basic } \\
\text { Medical } \\
\text { Care }\end{array}$ & -0.57 & 0.38 & -0.03 & -0.25 & -0.16 & 0.57 \\
\hline $\begin{array}{c}\text { Water } \\
\text { and } \\
\text { Sanitatio } \\
\text { n }\end{array}$ & -0.30 & 0.31 & 0.18 & -0.11 & -0.06 & 0.50 \\
\hline Shelter & -0.62 & 0.63 & 0.02 & -0.62 & -0.04 & 0.70 \\
\hline $\begin{array}{c}\text { Personal } \\
\text { Safety }\end{array}$ & -0.34 & 0.14 & -0.14 & -0.42 & -0.24 & 0.64 \\
\hline $\begin{array}{c}\text { pillar 2: } \\
\text { Foundat } \\
\text { ions of } \\
\text { Wellbein } \\
\mathrm{g}\end{array}$ & -0.54 & 0.48 & -0.12 & -0.43 & -0.23 & 0.80 \\
\hline $\begin{array}{c}\text { Access to } \\
\text { Basic }\end{array}$ & -0.34 & 0.29 & -0.28 & -0.11 & -0.16 & 0.13 \\
\hline
\end{tabular}


Issue no. 22/2017

\begin{tabular}{|c|c|c|c|c|c|c|}
\hline $\begin{array}{c}\text { Knowled } \\
\text { ge }\end{array}$ & & & & & & \\
\hline $\begin{array}{l}\text { Access to } \\
\text { IT\&C }\end{array}$ & -0.55 & 0.61 & -0.15 & -0.70 & 0.03 & 0.62 \\
\hline $\begin{array}{c}\text { Health } \\
\text { and } \\
\text { Wellness }\end{array}$ & -0.24 & 0.13 & 0.06 & -0.13 & -0.36 & 0.70 \\
\hline $\begin{array}{c}\text { Environ } \\
\text { mental } \\
\text { Quality }\end{array}$ & -0.59 & 0.51 & -0.20 & -0.36 & -0.14 & 0.69 \\
\hline $\begin{array}{c}\text { pillar 3: } \\
\text { Opportu } \\
\text { nity }\end{array}$ & -0.60 & 0.47 & -0.18 & -0.51 & -0.32 & 0.80 \\
\hline $\begin{array}{c}\text { Personal } \\
\text { Rights }\end{array}$ & -0.44 & 0.33 & -0.16 & -0.42 & -0.19 & 0.53 \\
\hline $\begin{array}{c}\text { Personal } \\
\text { Freedom } \\
\text { and } \\
\text { Choice }\end{array}$ & -0.59 & 0.47 & -0.28 & -0.52 & -0.20 & 0.75 \\
\hline $\begin{array}{c}\text { Toleranc } \\
\text { e and } \\
\text { Inclusion }\end{array}$ & -0.55 & 0.32 & -0.13 & -0.41 & -0.45 & 0.85 \\
\hline $\begin{array}{c}\text { Access to } \\
\text { Advance } \\
\text { d } \\
\text { Educatio } \\
\mathrm{n}\end{array}$ & -0.56 & 0.62 & -0.03 & -0.44 & -0.23 & 0.66 \\
\hline
\end{tabular}

Source: own calculations on data provided by Porter and Stern (2016), Hofstede (2001) and

Hofstede, Hofstede and Minkov (2010). 
As highlighted in Table 1, the most relevant cultural dimension in the context of social progress is indulgence vs. restraint, which exhibits high levels of association with the overall Social Progress Index $(r=0.83)$ and all three of its pillars $(r=0.73,0.80$ and 0.80 for the basic and human needs, foundations of wellbeing and opportunity pillars respectively). The strong positive correlation levels observed indicates that there may be a causal connection between indulgent societies and social progress, as the cultural dimension's intrinsic elements like perceptions of personal life control, the importance of freedom of speech and a higher importance of leisure (Hofstede, 2011) seem to contribute to the creation of a catalytic environment for social progress along the three vectors taken into consideration.

Regarding the other Hofstede's cultural dimensions, one can observe somewhat lower, but still above threshold, correlation levels between:

1. the power distance dimension (or the degree of acceptance by less powerful group members of the unequal distribution of power) and overall social progress (with notable levels regarding the opportunity pillar and shelter), the negative correlation indicating that small power distance - which, according to Hofstede (2011), means, among others, that the use of power is governed by legitimacy, that there is a low tolerance for corruption and that income is distributed rather even - could contribute to a higher level of social progress, with accents on the opportunity pillar and shelter;

2. the uncertainty avoidance dimension and access to information and communication and shelter, signaling that a low level of uncertainty avoidance could be a factor in ensuring access and vice-versa, although this study has found no evidence that could indicate clear causation. Moreover, even in the presence of a connection, it is unclear whether the attitude towards uncertainty modulates social progress or it is the other way around and socially advanced societies tend to shape uncertainty avoidance mainly via its structural values which, according to Hofstede (2011), include the tolerance of deviant persons and ideas (high when uncertainty avoidance is weak and low when uncertainty 
avoidance is strong), which could be relevant for access to information and communication;

3. the individualism vs. collectivism dimension and the access to information and communication, shelter and advanced education. In this case, the exhibited positive association levels, indicating that individualistic societies are prone to being more socially advanced, are not only counterintuitive, but also lacking any type of evidence that would indicate causality, thus determining the classification of the observed correlation levels as irrelevant.

These results are consistent with the correlation results between social progress and the cultural elements as defined and measured by Schwartz $(1999,2006)$, as detailed in Table $2^{18}$.

Table 2: Association levels between the components of the Social Progress Index and Schwartz's cultural dimensions in the European Union

\begin{tabular}{|c|r|r|r|r|r|r|r|}
\hline & Embeddedness & $\begin{array}{r}\text { Affective } \\
\text { autonomy }\end{array}$ & $\begin{array}{r}\text { Intellectual } \\
\text { autonomy }\end{array}$ & Mastery & Harmony & Hierarchy & Egalitarianism \\
\hline $\begin{array}{c}\text { Social } \\
\text { Progress } \\
\text { (overall) }\end{array}$ & -0.75 & 0.65 & 0.60 & -0.23 & 0.02 & -0.38 & 0.71 \\
\hline $\begin{array}{c}\text { pillar 1: Basic } \\
\text { Human } \\
\text { Needs }\end{array}$ & -0.24 & 0.42 & 0.45 & 0.55 & -0.59 & -0.28 & 0.87 \\
\hline $\begin{array}{c}\text { Nutrition and } \\
\text { Basic Medical } \\
\text { Care }\end{array}$ & -0.38 & 0.37 & 0.32 & -0.29 & 0.10 & -0.29 & 0.53 \\
\hline Water and & -0.38 & 0.27 & 0.23 & -0.22 & 0.25 & -0.19 & 0.50 \\
\hline
\end{tabular}

\footnotetext{
${ }^{18}$ Croatia, Cyprus, Lithuania, Luxembourg and Malta are absent due to the lack of available data. Values for Germany refer to West Germany only.
} 


\begin{tabular}{|c|c|c|c|c|c|c|c|}
\hline \multicolumn{8}{|l|}{ Sanitation } \\
\hline Shelter & -0.67 & 0.60 & 0.46 & -0.26 & 0.05 & -0.26 & 0.51 \\
\hline \multicolumn{8}{|l|}{ Personal } \\
\hline Safety & -0.44 & 0.46 & 0.33 & -0.21 & -0.09 & -0.16 & 0.20 \\
\hline \multicolumn{8}{|l|}{ pillar 2: } \\
\hline \multicolumn{8}{|l|}{ Foundations } \\
\hline of Wellbeing & -0.80 & 0.65 & 0.63 & -0.17 & 0.16 & -0.44 & 0.80 \\
\hline \multicolumn{8}{|l|}{ Access to } \\
\hline \multicolumn{8}{|l|}{ Basic } \\
\hline Knowledge & -0.23 & 0.14 & 0.14 & -0.22 & -0.01 & -0.18 & 0.37 \\
\hline \multicolumn{8}{|l|}{ Access to } \\
\hline $\mathrm{IT} \& \mathrm{C}$ & -0.55 & 0.49 & 0.35 & -0.36 & -0.04 & -0.21 & 0.35 \\
\hline \multicolumn{8}{|l|}{ Health and } \\
\hline Wellness & -0.57 & 0.42 & 0.42 & 0.25 & 0.03 & -0.34 & 0.82 \\
\hline \multicolumn{8}{|l|}{ Environmental } \\
\hline Quality & -0.82 & 0.68 & 0.75 & -0.32 & 0.39 & -0.49 & 0.69 \\
\hline \multicolumn{8}{|l|}{ pillar 3: } \\
\hline Opportunity & -0.71 & 0.62 & 0.59 & -0.23 & -0.06 & -0.37 & 0.69 \\
\hline \multicolumn{8}{|l|}{ Personal } \\
\hline Rights & -0.28 & 0.20 & 0.24 & -0.32 & -0.05 & -0.33 & 0.53 \\
\hline \multicolumn{8}{|l|}{ Personal } \\
\hline \multicolumn{8}{|l|}{ Freedom and } \\
\hline Choice & -0.70 & 0.70 & 0.58 & -0.27 & -0.11 & -0.29 & 0.50 \\
\hline \multicolumn{8}{|l|}{ Tolerance and } \\
\hline Inclusion & -0.80 & 0.67 & 0.68 & -0.07 & 0.00 & -0.37 & 0.72 \\
\hline \multicolumn{8}{|l|}{ Access to } \\
\hline \multicolumn{8}{|l|}{ Advanced } \\
\hline Education & -0.67 & 0.55 & 0.53 & -0.19 & -0.06 & -0.26 & 0.66 \\
\hline
\end{tabular}

Source: own calculations on data provided by Porter and Stern (2016) and Schwartz $(1999,2006)$ 
The analysis reveals that two cultural value classes could prove to be relevant in the quest for identifying factors that influence social progress, namely embeddedness and egalitarianism. Of course, their opposites, i.e. autonomy and hierarchy, seem to exhibit contrary effects.

On one hand, the observed negative association levels indicate that when societies are marked by a high degree of embeddedness, meaning focus placed on the maintenance of traditional order, the social environment seems to be less developed $(r=-0.75)$, with emphasis on the foundations of wellbeing $(r=-0.80)$ and opportunity pillars $(r=-0.71)$ and their constituent value classes related to environmental quality $(r=-0.82)$, personal freedom and choice $(r=-0.71)$ and tolerance and inclusion $(r=-0.80)$.

Regarding the pair formed by embeddedness and the basic human needs pillar, data suggests that there is no real connection.

On the other hand, societies with a high level of egalitarianism, i.e. that extensively recognize that all members of society are equal from a moral standpoint, seem more likely to be socially advanced. More precisely, there is a high positive correlation level between this cultural characteristic and the value of the social progress index $(\mathrm{r}=0.71)$. Breaking this down, one can notice high positive correlation with the basic human needs pillar $(\mathrm{r}=0.87)$, the foundations of wellbeing pillar $(\mathrm{r}=0.80)$ and a moderate to high level with the opportunity pillar ( $\mathrm{r}=0.69$ ), with the health and wellbeing and the tolerance and inclusion value classes standing out as having a stronger connection.

Even though most of these associations are in line with what we would expect from the structure of the value pillars and classes, the quantitative confirmation of this intuition allows for these results to be considered as valid inputs for policy making and policy implementation processes.

Social progress is without doubt influenced by social expenditure, so further investigation must be done to understand how this connection affects the nature of the relation between elements characterizing culture and social progress. 
A first step in this direction is represented by the analysis of association levels between culture and social expenditure. Since the isolation of the wealth variable is essential for obtaining reliable results, social expenditure/GDP per capita is to be used. The observed association levels are described in Table $3^{19}$.

Table 3: Correlations between cultural dimensions and total social expenditure/ GDP per capita

\begin{tabular}{|c|c|}
\hline & Correlation \\
\hline \multicolumn{2}{|c|}{ Hofstede's dimensions } \\
\hline Power Distance & -0.53 \\
\hline Individualism (vs. collectivism) & 0.46 \\
\hline Masculinity (vs. femininity) & -0.17 \\
\hline Uncertainty avoidance & -0.40 \\
\hline Long term orientation & -0.23 \\
\hline Indulgence (vs. restraint) & 0.84 \\
\hline \multicolumn{2}{|c|}{ Schwartz's dimensions } \\
\hline Embeddedness & -0.87 \\
\hline Affective autonomy & 0.80 \\
\hline Intellectual autonomy & 0.75 \\
\hline Mastery & -0.09 \\
\hline Harmony & 0.08 \\
\hline Hierarchy & -0.38 \\
\hline Egalitarianism & 0.75 \\
\hline
\end{tabular}

Source: own calculations on data provided by Eurostat, Pordata, Hofstede (2001), Hofstede, Hofstede and Minkov (2010) and Schwartz (1999, 2006).

The results indicate that the same cultural variables that are associated with key social progress drivers are correlated with how much a country spends on social policies

\footnotetext{
${ }^{19}$ Same restrictions as mentioned before apply regarding data considered.
} 
relative to its GDP per capita. More precisely, along Hofstede's dimensions, indulgence is strongly positively correlated with social expenses $(\mathrm{r}=0.84)$, while power distance exhibits lower but still relevant negative association $(r=-0.53)$. Similarly, along Schwartz's dimensions, embeddedness and egalitarianism are strongly correlated with total social expenditure $(r=-0.87$ and $r=0.75$ respectively). Also, strong positive association can be observed when it comes to autonomy, which is a natural occurrence given the strong negative correlation between social progress and embeddedness, autonomy's conceptual opposite.

The results must be interpreted in the context of the fact that total social expenditure/GDP per capita exhibits strong positive correlation levels with social progress $(\mathrm{r}=0.83)$, the foundations of wellbeing pillar $(\mathrm{r}=0.86)$, borderline strong with the opportunity pillar $(\mathrm{r}=0.79)$ and moderate to strong with the basic human needs pillar $(\mathrm{r}=0.66)$. Since it is obvious that social expenditure levels are not a determinant of cultural characteristics and recognizing the fact that culture embeds preferences that transpire into policy, these findings are indicative of the structure of the causal chain linking cultural dimensions and values to elements pertinent to social progress, i.e. from culture via expenditure levels to social progress and its pillars, especially those referring to foundations of wellbeing and opportunity. Such a dynamic supports the causal argument pointing out that certain cultural elements are relevant to social outcomes, thus constituting an important guideline for more effective and efficient culturally adapted social policy design and implementation.

\section{Conclusion}

Adopting a comprehensive view on social policy design and implementation that includes a cultural perspective is especially important in an EU environment that, as Păun and Corpădean (2015) notice, is marked by a series of socio-political contradictions that run the risk of becoming structural. The resulting losses in political consensus could be 
restored by engaging in a serious debate that includes, among others, the cultural dimension of the EU project, an issue that has lately generated a lot of interest (Ciceo, 2016).

In this context, the paper contributes to revealing the connections between cultural elements and social progress. The data analyzed shows that, within this complex environment, a series of cultural characteristics like indulgence, embeddedness and egalitarianism play, through their influence on social expenditure, a causal role in social development processes.

As a final remark, it must be understood that this paper should be interpreted as depicting an initial stage in a more complex research, its objective being that of providing with intermediary results that allow the channeling of subsequent stages in the right direction. In this line, the current findings are instrumental for further research aimed at identifying and understanding all the causal mechanisms that link culture with social outcomes, the end objective of such an endeavor being the application of this understanding in policymaking, more precisely enabling the design of more effective and efficient, culturally adapted social policies.

\section{References}

- ALBESCU, Oana and MANIU, Mircea (2015), "Convergence theory revisited: social entrepreneurship", in MIȘCOIU, Sergiu and NAUMESCU Valentin (eds.), What is left from the right-left cleavage, Bucharest: ISPRI, pp. 207-232.

- ASUERO A. G., SAYAGO, A. and GONZALEZ A. G. (2006), "The Correlation Coefficient: An Overview", Critical Reviews in Analytical Chemistry, No. 36, pp. 4159 , available

online at

https://metodologiacomportamiento.files.wordpress.com/2009/05/the-correlationcoefficient-an-overview.pdf (15.04.2017). 
- CICEO, Georgiana (2010), "Reshaping the Structures of Global Governance. What Lessons Are to be Learnt from the Latest Financial Crisis?", Annals of University of Oradea, Series: International Relations and European Studies, Vol. 2, pp. 116-130.

- CICEO, Georgiana (2016), “The Difficult Path towards Europeanness. Assessing the Politics of Culture and Identity in The European Union", On-line Journal Modelling the New Europe, No. 19, pp. 6-17.

- DAN, Horatiu (2015), "The Influence of Cultural Elements on Fiscal Behaviour in the European Union”, On-line Journal Modelling the New Europe, No. 16, pp. 3-19.

- GERRING, John (2005), "Causation: A Unified Framework for the Social Sciences", Journal of Theoretical Politics, Vol. 17, No. 2, pp. 163-198.

- GRAHL, John and TEAGUE, Paul (2013), "Reconstructing the eurozone: the role of EU social policy", Cambridge Journal of Economics, No, 37, pp. 677-692.

- HOFSTEDE, Geert (1980), Culture's Consequences: International Differences in Work-Related Values, Beverly Hills, CA: Sage Publications.

- HOFSTEDE, Geert (2001), Culture's Consequences: Comparing Values, behaviours, Institutions, and Organizations across Nations, $2^{\text {nd }}$ edition, Thousand Oaks CA: Sage Publications.

- HOFSTEDE, Geert (2011), "Dimensionalizing Cultures: The Hofstede Model in Context", Online Readings in Psychology and Culture, No. 2(1), available online at http://scholarworks.gvsu.edu/cgi/viewcontent.cgi?article $=1014 \&$ context $=$ orpc (09.04.2017).

- HOFSTEDE, Geert; HOFSTEDE, Gert Jan and MINKOV, Michael (2010), Cultures and Organizations: Software of the Mind, $3^{\text {rd }}$ edition, New York: McGraw-Hill USA.

- IBĂNESCU, Andreea; RACOLȚA-PAINA, Nicoleta Dorina and IONESCU, Dan (2015), “Managers' Perceptions Regarding Management Challenges and the 
Development of Romanian SMEs. Selected Findings From 2012-2015”, On-line Journal Modelling the New Europe, No. 16, pp. 20-42.

- JONES, M. L., Hofstede - Culturally Questionable?, Oxford Business \& Economics Conference. Oxford, UK, 24-26 June, 2007.

- PĂUN, Ciprian and CORPĂDEAN, Adrian-Gabriel (2015), "European Regions and Multiculturalisms: Beyond the Nation?", Transylvanian Review, Vol. 24, Sup. 1, pp. 55-64.

- PĂUN, Dragoș (2013), "The Impact of the Euro in the Modern Economy Context", Studia Universitatis Babeș-Bolyai. Studia Europaea, Vol. 58, No. 3, pp. 107-132.

- PORTER, Michael (2013), cited in CONFINO, Jo, "Michael Porter unveils new health and happiness index", The Guardian, $11^{\text {th }}$ of April 2013, available online at https://www.theguardian.com/sustainable-business/michael-porter-health-happinessindex (01.04.2017).

- PORTER, Michael and STERN, Scott (2016), "Social Progress Index 2016”, Social Progress Imperative, Washington, D.C, available online at http://www.socialprogressimperative.org/wp-content/uploads/2016/06/SPI-2016-MainReport.pdf, (01.04.2017).

- RACOLŢA-PAINA, Nicoleta Dorina and IONESCU, Dan (2010), "Current Cultural and Organizational Realities in Romania, Using Applied Research to Bridge the Gap between Western Management Theories and Local Management Practices", in ABRUDAN, Ioan (Ed.) Proceedings of the $1^{\text {st }}$ Management Conference: Twenty Years After - How Management Theory Work, Todesco Publishing House, pp. 485-494.

- RICHARDSON, Grant (2008), "The relationship between culture and tax evasion across countries: Additional evidence and extensions", Journal of International Accounting, Auditing and Taxation, No. 17, pp. 67-78.

- SCHWARTZ, Shalom (1999), “A Theory of Cultural Values and Some Implications for Work", Applied Psychology: An International Review, Vol. 48, No. 1, pp. 23-46. 
- SCHWARTZ, Shalom (2006), “A Theory of Cultural Value Orientations: Explication and Applications", Comparative Sociology, Vol. 5, No. 2-3.

- STEENKAMP, Jan-Benedict (2001), "The role of national culture in international marketing research", International Marketing Review, Vol. 18, No. 1, pp. 30-44.

- TAYLOR, Richard (1990), "Interpretation of the Correlation Coefficient: A Basic Review”, Journal of Diagnostic Medical Sonography, No. 1, Vol. 6, pp. 35-39.

- ZADY, Madelon F. (2000), Z-12: Correlation and Simple Least Squares Regression, available online at https://www.westgard.com/lesson42.htm (15.04.2017). 